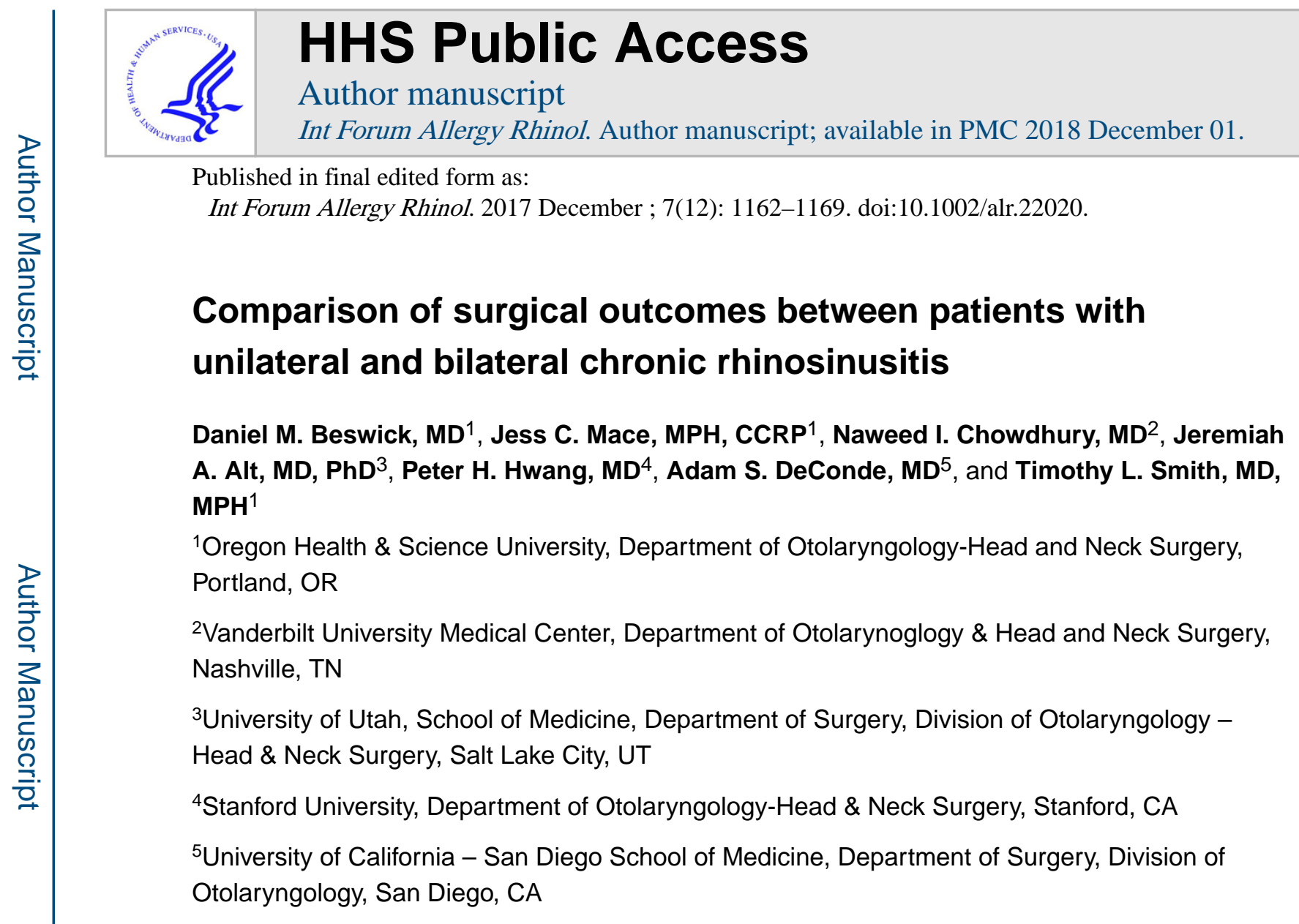

\title{
Abstract
}

Background-Although the majority of patients with chronic rhinosinusitis without nasal polyposis (CRSsNP) suffer from bilateral disease, a subset suffer from unilateral disease. Currently, outcomes following endoscopic sinus surgery (ESS) for medically recalcitrant CRS are inferred from outcomes for patients with bilateral disease. This study compares outcomes of ESS between patients with unilateral and bilateral disease.

Methods-Patients with CRSsNP who failed appropriate medical therapy and elected ESS were enrolled between 2011 and 2015. Patients were dichotomized according to radiographic evidence of unilateral disease (Lund-Mackay (LM) score $=0$ for one side) or bilateral disease (LM $\geq 1$ for both sides). The primary outcome of interest was the 22-item Sinonasal Outcome Test (SNOT-22),

CORRESPONDING AUTHOR: Timothy L. Smith, MD, MPH, Oregon Health \& Science University, Department of Otolaryngology - Head and Neck Surgery, Division of Rhinology and Sinus/Skull Base Surgery, Oregon Sinus Center, 3181 SW Sam Jackson Park Road, PV-01, Portland, OR. 97239, smithtim@ohsu.edu, Phone: 503-494-7413, FAX: 503-494-4631.

Potential Conflicts of Interest: None

Financial Disclosures: Timothy L. Smith, Jeremiah A. Alt, Peter H. Hwang, and Jess C. Mace were supported by a grant for this investigation from the National Institute on Deafness and Other Communication Disorders (NIDCD), one of the National Institutes of Health, Bethesda, MD., USA (R01 DC005805; PI: T. Smith). Public clinical trial registration (www.clinicaltrials.gov) ID\# NCT02720653. The NIDCD did not contribute to the design or conduct of this study; preparation, review, approval or decision to submit this manuscript for publication. There are no relevant financial disclosures for Daniel M. Beswick or Naweed I. Chowdhury. Peter H. Hwang is also consultant for Medtronic, 480 Biomedical, and Arrinex, with no affiliations to this investigation. Adam S. DeConde is a consultant for Intersect ENT, Stryker Endoscopy, and Olympus, with no affiliations to this investigation. Jeremiah A. Alt is a consultant for Medtronic, Spirox, and GlycoMira Therapeutics, none of which were affiliated with this investigation.

The abstract for this manuscript was accepted for a podium presentation to the American Rhinologic Society during the American Academy of Otolaryngology-Head and Neck Surgery Annual Meeting \& OTO Experience in Chicago, IL, September, 2017. 
with secondary outcomes including the Brief Smell Identification Test (BSIT) and the LundKennedy (LK) endoscopy staging system.

Results-190 patients met inclusion criteria consisting of 19 with unilateral (10\%) and 171 with bilateral CRSsNP (90\%). Both groups were similar across all preoperative demographic factors, SNOT-22 and BSIT scores. Postoperatively, patients with bilateral disease reported greater improvement in mean SNOT-22 scores compared to unilateral disease, but this difference was not statistically or clinically significant $(-24.3[ \pm 21.1]$ vs. $-21.5[ \pm 24.0], p=0.582)$. Mean LK scores improved for patients with bilateral disease but not unilateral disease without a difference between groups $(-2.0[ \pm 3.5]$ vs. $-0.4[ \pm 2.4], \mathrm{p}=0.090)$.

Conclusions-Patients with unilateral CRSsNP experience improvement after ESS comparable to patients with bilateral disease on patient reported outcome measures.

\section{Medical Subject Headings}

Sinusitis; chronic disease; patient outcome assessment; quality-of-life; sinus surgery

\section{INTRODUCTION}

Chronic rhinosinusitis (CRS) is a chronic inflammatory disease that affects up to $15 \%$ of the United States (US) population. ${ }^{1-3}$ While the majority of patients with chronic rhinosinusitis without nasal polyposis (CRSsNP) suffer from bilateral disease, a subset suffer from unilateral disease. Although the prevalence of unilateral CRS in the US is challenging to quantify, unilateral CRS is relatively common. A retrospective study of patients who underwent endoscopic sinus surgery demonstrated that almost $25 \%$ had unilateral sinonasal disease and that CRS was the most common diagnosis among this group. ${ }^{4}$ While multiple etiologies exist for unilateral sinonasal disease, CRS remains the most common diagnosis for patients with unilateral disease requiring surgical intervention. ${ }^{4,5}$

Treatment outcome investigations for endoscopic sinus surgery (ESS) in patients with CRS do not typically differentiate between unilateral and bilateral disease. To our knowledge only one prior study has evaluated outcomes following ESS for unilateral and bilateral chronic rhinosinusitis in those patients with nasal polyposis (CRSwNP). ${ }^{6}$ No prior studies have evaluated this potential difference in a population with CRSsNP. A better understanding of postoperative improvements between unilateral and bilateral CRS would facilitate improved decision-making and patient counseling. This investigation attempted to characterize postoperative changes in both patient-reported outcome measures and clinical measures of disease severity between unilateral and bilateral disease in patients with CRSsNP.

\section{MATERIALS and METHODS}

\section{Study Population}

Adult study participants ( $\geq 18$ years of age) were prospectively enrolled into a multi-center, observational cohort study evaluating treatment outcomes following ESS. Results from this investigation have been previously described. ${ }^{7-10}$ Participants were diagnosed by fellowship-trained rhinologists with recalcitrant CRS defined by current diagnostic 
guidelines to involve radiographic indication of disease. ${ }^{2,11-13}$ Before electing ESS as a subsequent treatment modality all participants had completed initial therapeutics including, but not limited to, daily saline irrigation, at least one course of either topical corticosteroids ( $\geq 21$ days) or a 5+ day course of oral corticosteroid therapy, and at least one course ( $\geq 14$ days) of broad spectrum or culture-directed antibiotics.

The Institutional Review Board (IRB) at each enrollment site governed investigational protocols and informed consent procedures. Enrollment locations included sinus clinics within tertiary referral, academic hospital systems in the US including: Oregon Health \& Science University (OHSU; Portland, OR; IRB\#7198), Stanford University (Palo Alto, CA; IRB\#4947), and the University of Utah (Salt Lake City, UT; IRB\#61810). Patients were assured of minimal study risk, voluntary study consent, and standard of care would not be altered due to study participation.

Enrollment procedures occurred after study participants underwent surgical counseling and voluntarily elected ESS. Study participants provided a comprehensive history and followed through the standard of postoperative care for 18 months. Participants were asked to complete both preoperative and postoperative evaluations at approximate 6-month intervals, either during physician-directed appointments or follow-up mailings when applicable.

\section{Exclusion Criteria}

Study participants were considered lost to follow-up and excluded if they did not provide any postoperative follow-up evaluation ( $\geq 6$ months) during the study duration. Additional participants with comorbid cystic fibrosis or primary ciliary dyskinesia were excluded from final analysis due to variation in global health status and differential treatment considerations in the standard of care.

\section{Endoscopic Sinus Surgery}

Surgical extent was dictated by the enrolling physician and guided by symptomatic, radiographic, and endoscopic indications of disease severity and conducted under general anesthesia. Patients were either primary or revision ESS cases consisting of unilateral or bilateral maxillary antrostomy, partial or total ethmoidectomy, sphenoidotomy, or frontal sinusotomy (IIa, IIb, or III) procedures. Inferior turbinate reduction and septoplasty were conducted as adjunctive procedures when necessary to improve the nasal airway. All patients were followed with appropriate postoperative therapeutic regimens, including daily nasal saline irrigation, topical corticosteroid sprays/rinses, and other appropriate medical therapy as determined necessary by the enrolling surgeon.

\section{Clinical Outcome Measures}

Study participants completed the 22-item SinoNasal Outcome Test (SNOT-22), a validated instrument developed to quantify sinonasal symptom severity (@2006, Washington University, St. Louis, MO).${ }^{14}$ Discrete item scores are measured using Likert scale responses (score range: $0-5$ ) where higher scores indicate worse symptom severity as follows: $0=$ 'No problem'; 5='Problem as bad as it can be'. Higher total scores on the SNOT-22 reflect worse daily functioning and/or symptom severity (score range: $0-110$ ). The 22 -items of the 
SNOT-22 survey have been categorized and summarized into 5 distinct domains including: rhinologic symptom domain (score range: 0-30), extra-nasal rhinologic symptom domain (score range: 0-15), ear / facial symptom domain (score range: 0-25), psychological dysfunction domain (score range: $0-35$ ), and the sleep dysfunction domain (score range: 0 25) as previously described. ${ }^{15}$ Participants were asked to complete the SNOT-22 both preoperatively and during each postoperative follow-up evaluation.

Olfactory function was also measured in study participants using the Brief Smell Identification Test (BSIT, Sensonics, Inc., Haddon Heights, NJ) during both preoperative and postoperative follow-up evaluations. The BSIT is a validated, 12-item, cross-cultural diagnostic tool of olfactory identification utilizing microencapsulated odorant strips with a 'forced choice' response format. Study participants are directed to identify each discrete odorant from 1 correct response and 3 distractor responses. The BSIT is designed with 'scratch-and-sniff' odorant strips, which are activated with standard \#2 pencil strikes. Higher total BSIT scores reflect superior olfactory function (score range: $0-12$ ) while BSIT scores $\geq$ 9 are clinically interpreted as 'normal' olfaction for healthy males and females of all ages. Total BSIT scores $\leq 8$ are clinically interpreted as either reduced olfactory identification capacity or patient malingering, although alternative scoring thresholds have been proposed for subjects with CRS. ${ }^{16-18}$

The paranasal sinuses were examined bilaterally using $0-30^{\circ}$ rigid endoscopy (Karl Storz, Tuttlingen, Germany) and graded by each enrolling physician using Lund-Kennedy (LK) staging (score range: 0-20) which quantifies the presence and severity of nasal polyposis, discharge, edema, scarring, and crusting. ${ }^{19}$ Higher scores reflect worse overall disease severity. Endoscopic evaluations were completed both preoperatively and during each follow-up, when possible, per the standard of care.

\section{Lund-Mackay Computed Tomography}

High resolution computed tomography (CT) imaging was also utilized to evaluate preoperative sinonasal disease severity using $1.0 \mathrm{~mm}$. contiguous images in both sagittal and coronal planes. Images were staged by the enrolling physician following the Lund-Mackay bilateral scoring system (bilateral score range: 0-24) which quantifies image opacification severity in the maxillary, ethmoidal, sphenoidal, ostiomeatal complex, and frontal sinus regions for each right and left side. ${ }^{20}$ Postoperative CT images were not collected due to elevated risk of radiation exposure and divergence from the standard of care. Higher scores on the Lund-Mackay staging system indicate worse overall disease severity. As the primary exposure variable of interest, study participants were further classified as either having unilateral (score range: $0-12$ ) or bilateral CRS per determinations of their preoperative CT imaging (Figure 1). Patients with unilateral CRS (LM=0 on one side) due to an atypical etiology such as mucocele or odontogenic disease were separated from primary analyses since atypical cases may associate with different outcomes compared to non-atypical unilateral CRS disease. 


\section{Data Management and Statistical Analyses}

De-identified participant study data was coded with unique study numbers to ensure confidentiality and transferred to OHSU from each enrollment site for data compilation and analysis. Study data was manually entered into a HIPAA compliant relational database (Access, Microsoft Corp., Redmond, WA) and statistical analyses were conducted using commercial software (SPSS v.23, IBM Corp., Armonk, NY). Last available SNOT-22, BSIT, and endoscopy scores were used to operationalize postoperative evaluations due to previously reported similarity of mean postoperative scores between 6,12 , and 18 month follow-up in this cohort ${ }^{21,22}$ Postoperative improvement was determined by subtracting preoperative scores from postoperative scores and averaged. Descriptive analytics are reported while comparisons in preoperative measures while between-group differences were evaluated using either two-sided independent sample t-tests, Mann-Whitney U tests, or Pearson's chi-square testing, based on scale distribution or count frequency. Within-subject improvements in clinical outcome measures was evaluated using either match paired sample t-tests or Wilcoxon signed rank testing.

\section{RESULTS}

\section{Final Study Cohort}

A total of 196 enrolled study participants with CRSsNP met inclusion and exclusion criteria and underwent ESS between April, 2011 and October, 2015. Six study participants diagnosed with unilateral atypical CRS, consisting of comorbid mucocele $(\mathrm{n}=1)$, odontogenic CRS $(n=1)$, fungal ball $(n=2)$, hemangioma $(n=1)$, and frontal osteoma $(n=1)$, were separated from primary analyses due to atypical etiology. Participants $(n=190)$ reported an average of 52.8 [ \pm 14.5$]$ years of age (range: $18-82$ ) and were followed for a mean of 16.1 [ \pm 4.8$]$ months after ESS (range: 5 - 29). Final study cohort characteristics, preoperative clinical outcome measures, and computed tomography scoring are compared in Table 1 between study participants with unilateral CRS $(\mathrm{n}=19 ; 10 \%, 9$ with right-sided disease and 10 with left-sided disease) and bilateral CRS ( $\mathrm{n}=171 ; 90 \%)$. Participants with unilateral CRS were similar to patients with bilateral CRS across all demographic factors, comorbid characteristics, SNOT-22 scores, and olfactory test results. Of the 19 unilateral patients, 10 (53\%) had septal deviation, 7 with leftward and 3 with rightward deviation. As anticipated, the Lund Mackay total score was significantly different between groups per the definition of the primary exposure of interest for this study. The frequency of ESS procedures is described in Table 2 for both unilateral and bilateral groups.

\section{Postoperative Improvement in Outcome Measures}

Within-subject and between-subject postoperative improvement in clinical outcome measure scores were evaluated for both patients with unilateral and bilateral CRS without covariate adjustment (Table 3 ). Statistically significant within-subject improvement was reported by subjects with bilateral CRSsNP across all SNOT-22 scores $(\mathrm{p}<0.001)$ and endoscopy measures $(\mathrm{p}<0.001)$ after ESS. Study participants with unilateral CRS reported similar mean improvements over time in SNOT-22 scores ( $\mathbf{0 . 0 1 2}$ ), with the exception of the ear/facial symptom domain $(\mathrm{p}=0.085)$. Significant postoperative changes in mean BSIT scores were 
not found for either group ( $>0.600$ ). Nasal endoscopy scores did not improve in those with unilateral CRS $(\mathrm{p}=0.289)$.

\section{Subgroup Analysis Within Unilateral CRS}

Study participants with unilateral CRS were further compared across preoperative cohort characteristic measures (Table 4), surgical procedure type (Table 5), and postoperative improvement in clinical outcome measures (Table 6) between those with $(\mathrm{n}=6 ; 24 \%)$ and without atypical ( $\mathrm{n}=19 ; 76 \%) \mathrm{CRS}$ as described. Study participants with atypical CRS diagnoses reported significantly lower (better) mean preoperative SNOT-22 total scores compared to typical unilateral CRS patients $(\mathrm{p}=0.009)$, primarily associated with lower (better) psychological and sleep dysfunction domain scores.

Due to limitations in sample size for both unilateral CRS groups, with and without atypical comorbidity, no significant differences in between-subject postoperative clinical outcome measures were noted (Table 6). Statistically significant within-subject improvement was reported by subjects with both atypical and typical unilateral CRS across all SNOT-22 scores, with the exception of ear/facial symptom domain scores in the typical unilateral CRS subgroup. No significant within-subject changes were found for either BSIT or endoscopy scores for either group.

\section{DISCUSSION}

This study evaluates outcomes following ESS for patients with unilateral CRSsNP compared to patients with bilateral disease in a multi-center, prospective cohort study. Patients with unilateral CRS experienced a significant decrement in their preoperative quality of life, similar to the level of patients with bilateral disease, in both total SNOT-22 and all subdomain scores. This is somewhat unexpected given the more limited extent of unilateral disease. Postoperatively, both groups achieved improvements in SNOT-22 scores greater than the minimum clinically important difference of 8.9 , representing a symptomatic improvement that is relevant to the individual patient. ${ }^{23}$ Subjects with both unilateral and bilateral disease demonstrate similar within-group changes in total SNOT-22, symptom domains, and BSIT scores postoperatively. LK endoscopy scores significantly improved only for the bilateral group; this may be due to the nature of scoring two sides compared to one, enabling a greater opportunity for improvement in the bilateral group, rather than an intrinsic difference between groups. Together this evidence suggests that patients with unilateral CRSsNP experience both preoperative quality of life (QOL) impairment and postoperative improvement after ESS comparable to patients with bilateral disease.

There is a growing body of evidence surrounding outcomes of CRS patients following ESS, including an expected improvement in QOL post-operatively. ${ }^{10,23-27}$ These studies do not differentiate between patients with unilateral and bilateral CRS, and as a result outcomes following ESS are inferred from outcomes for patients with bilateral disease. Thus, the understanding that patients with unilateral disease have similar outcomes to the bilateral group may improve counseling and surgical decision making for the former group by expanding the scope of the extensive bilateral CRS literature to include unilateral CRS patients. 
Patients with atypical unilateral CRS were found to have lower (better) mean preoperative SNOT-22 scores compared to typical unilateral CRS patients. This suggests that atypical etiologies of CRS may lead to a different symptom burden and distribution, including less psychiatric and sleep dysfunction, based on these findings.

No prior studies comparing unilateral to bilateral disease for patients with CRSsNP were identifiable. A single study from Korea comparing unilateral and bilateral CRSwNP demonstrated that SNOT-20 and visual analog symptom scores improved for both groups following surgery without statistically significant differences between groups. ${ }^{6}$ This study also found that patients with unilateral polyp disease were more likely to have 'good' endoscopic outcomes post-operatively, with 'good' defined as an absence of mucosal hypertrophy, inflammatory changes, purulent discharge, crust, synechia, or polyp recurrence. ${ }^{6}$ The portion of our findings comparing endoscopic scores between groups may differ from that study population. This is most likely due either a difference between the prevalence of CRSwNP and CRSsNP or different analytical approaches. Lee JY, et al. compared endoscopic exams in a binary fashion (essentially $L K=0$ vs $L K>0$ ) while the currently analysis compares the exact numerical value of the LK score between groups. Overall, the results of the current investigation herein are aligned with the primary finding of comparable improvement in SNOT survey scores in both patient subgroups.

In our analysis, significant postoperative changes in mean BSIT scores were not present in either group. Typically, improvements in olfaction are seen following ESS among patients with olfactory dysfunction, and anosmia and nasal polyposis have been associated with greater improvements. ${ }^{25,26,28}$ In this study, bilateral and unilateral groups had mean preoperative BSIT scores of 10.6 and 9.5, respectively, both in the normal range above $9.0,{ }^{17,18}$ which may have explained this lack of improvement. ${ }^{28}$

This study is subject to several limitations. All study participants received a confirmed diagnosis of CRS in a tertiary referral population, which may limit generalizability to the population at large. Relatively few patients were available for the atypical vs. typical unilateral comparison and the lack of significant postoperative differences may be an artifact of reduced power due to limited sample size.

\section{CONCLUSION}

Patients with unilateral CRSsNP experience similar deficits in QOL compared to patients with bilateral disease. The improvement in patients with unilateral disease after ESS is comparable to patients with bilateral disease on patient reported outcome measures. An understanding of this anticipated improvement may aid in decision-making and patient counseling.

\section{References}

1. Bhattacharyya N. Contemporary assessment of the disease burden of sinusitis. Am J Rhinol Allergy. 2009; 23:392-395. [PubMed: 19671253]

2. Orlandi RR, Kingdom TT, Hwang PH, et al. International Consensus Statement on Allergy and Rhinology: Rhinosinusitis. Int Forum Allergy Rhinol. 2016; 6(Suppl 1):S22-209. [PubMed: 26889651] 
3. Bhattacharyya N. Incremental health care utilization and expenditures for chronic rhinosinusitis in the United States. Ann Otol Rhinol Laryngol. 2011; 120:423-427. [PubMed: 21859049]

4. Lee JY. Unilateral paranasal sinus diseases: analysis of the clinical characteristics, diagnosis, pathology, and computed tomography findings. Acta Otolaryngol. 2008; 128:621-626. [PubMed: 18568494]

5. Paz Silva M, Pinto JM, Corey JP, Mhoon EE, Baroody FM, Naclerio RM. Diagnostic algorithm for unilateral sinus disease: a 15-year retrospective review. Int Forum Allergy Rhinol. 2015; 5:590-596. [PubMed: 25880633]

6. Lee JY, Byun JY, Shim SS, Lee SW. Outcomes after endoscopic sinus surgery for unilateral versus bilateral chronic rhinosinusitis with nasal polyposis. Am J Rhinol Allergy. 2010; 24:83-86. [PubMed: 20537280]

7. Alt JA, DeConde AS, Mace JC, Steele TO, Orlandi RR, Smith TL. Quality of Life in Patients With Chronic Rhinosinusitis and Sleep Dysfunction Undergoing Endoscopic Sinus Surgery: A Pilot Investigation of Comorbid Obstructive Sleep Apnea. JAMA Otolaryngol Head Neck Surg. 2015; 141:873-881. [PubMed: 26356240]

8. DeConde AS, Bodner TE, Mace JC, Alt JA, Rudmik L, Smith TL. Development of a clinically relevant endoscopic grading system for chronic rhinosinusitis using canonical correlation analysis. Int Forum Allergy Rhinol. 2016; 6:478-485. [PubMed: 26678860]

9. El Rassi E, Mace JC, Steele TO, Alt JA, Smith TL. Improvements in sleep-related symptoms after endoscopic sinus surgery in patients with chronic rhinosinusitis. Int Forum Allergy Rhinol. 2016; 6:414-422. [PubMed: 26678684]

10. Soler ZM, Hyer JM, Rudmik L, Ramakrishnan V, Smith TL, Schlosser RJ. Cluster analysis and prediction of treatment outcomes for chronic rhinosinusitis. J Allergy Clin Immunol. 2016; 137:1054-1062. [PubMed: 26806047]

11. Fokkens WJ, Lund VJ, Mullol J, et al. European Position Paper on Rhinosinusitis and Nasal Polyps 2012. Rhinol Suppl. 2012; 3:1-298. p preceding table of contents.

12. Rosenfeld RM, Andes D, Bhattacharyya N, et al. Clinical practice guideline: adult sinusitis. Otolaryngol Head Neck Surg. 2007; 137:S1-31. [PubMed: 17761281]

13. Rosenfeld RM, Piccirillo JF, Chandrasekhar SS, et al. Clinical practice guideline (update): adult sinusitis. Otolaryngol Head Neck Surg. 2015; 152:S1-S39.

14. Hopkins C, Gillett S, Slack R, Lund VJ, Browne JP. Psychometric validity of the 22-item Sinonasal Outcome Test. Clin Otolaryngol. 2009; 34:447-454. [PubMed: 19793277]

15. DeConde AS, Bodner TE, Mace JC, Smith TL. Response shift in quality of life after endoscopic sinus surgery for chronic rhinosinusitis. JAMA Otolaryngol Head Neck Surg. 2014; 140:712-719. [PubMed: 25074504]

16. Doty R. The Brief Smell Identification Test Administration Manual. 2001

17. Doty RL, Marcus A, Lee WW. Development of the 12-item Cross-Cultural Smell Identification Test (CC-SIT). Laryngoscope. 1996; 106:353-356. [PubMed: 8614203]

18. El Rassi E, Mace JC, Steele TO, et al. Sensitivity analysis and diagnostic accuracy of the Brief Smell Identification Test in patients with chronic rhinosinusitis. Int Forum Allergy Rhinol. 2016; 6:287-292. [PubMed: 26625169]

19. Lund VJ, Kennedy DW. Staging for rhinosinusitis. Otolaryngol Head Neck Surg. 1997; 117:S3540. [PubMed: 9334786]

20. Lund VJ, Mackay IS. Staging in rhinosinusitus. Rhinology. 1993; 31:183-184. [PubMed: 8140385]

21. DeConde AS, Mace JC, Alt JA, Rudmik L, Soler ZM, Smith TL. Longitudinal improvement and stability of the SNOT-22 survey in the evaluation of surgical management for chronic rhinosinusitis. Int Forum Allergy Rhinol. 2015; 5:233-239. [PubMed: 25511442]

22. Levy JM, Mace JC, Sansoni ER, Soler ZM, Smith TL. Longitudinal improvement and stability of olfactory function in the evaluation of surgical management for chronic rhinosinusitis. Int Forum Allergy Rhinol. 2016; 6:1188-1195. [PubMed: 27218483]

23. Soler ZM, Smith TL. Quality of life outcomes after functional endoscopic sinus surgery. Otolaryngol Clin North Am. 2010; 43:605-612. x. [PubMed: 20525514]

24. Rudmik L, Smith TL. Quality of life in patients with chronic rhinosinusitis. Curr Allergy Asthma Rep. 2011; 11:247-252. [PubMed: 21234819] 
25. Rudmik L, Smith TL. Olfactory improvement after endoscopic sinus surgery. Curr Opin Otolaryngol Head Neck Surg. 2012; 20:29-32. [PubMed: 22143338]

26. Soler ZM, Smith TL, Alt JA, Ramakrishnan VR, Mace JC, Schlosser RJ. Olfactory-specific quality of life outcomes after endoscopic sinus surgery. Int Forum Allergy Rhinol. 2016; 6:407-413. [PubMed: 26678351]

27. Tajudeen BA, Brooks SG, Yan CH, et al. Quality-of-life improvement after endoscopic sinus surgery in patients with obstructive sleep apnea. Allergy Rhinol (Providence). 2017; 8:25-31. [PubMed: 28381324]

28. DeConde AS, Mace JC, Alt JA, Schlosser RJ, Smith TL, Soler ZM. Comparative effectiveness of medical and surgical therapy on olfaction in chronic rhinosinusitis: a prospective, multiinstitutional study. Int Forum Allergy Rhinol. 2014; 4:725-733. [PubMed: 25044658] 

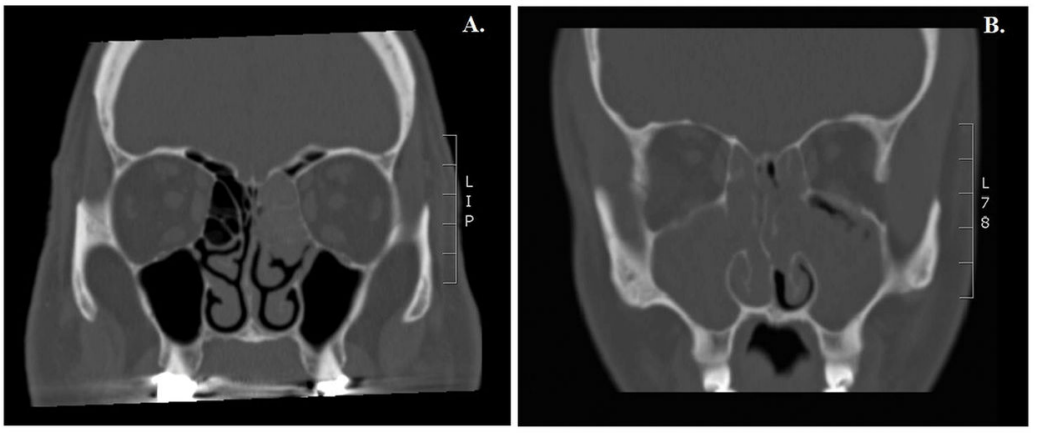

Figure 1.

Examples of unilateral (A) and bilateral (B) CRSsNP as exemplified on preoperative CT imaging. CT, computed tomography. CRSsNP, chronic rhinosinusitis without nasal polyposis. 


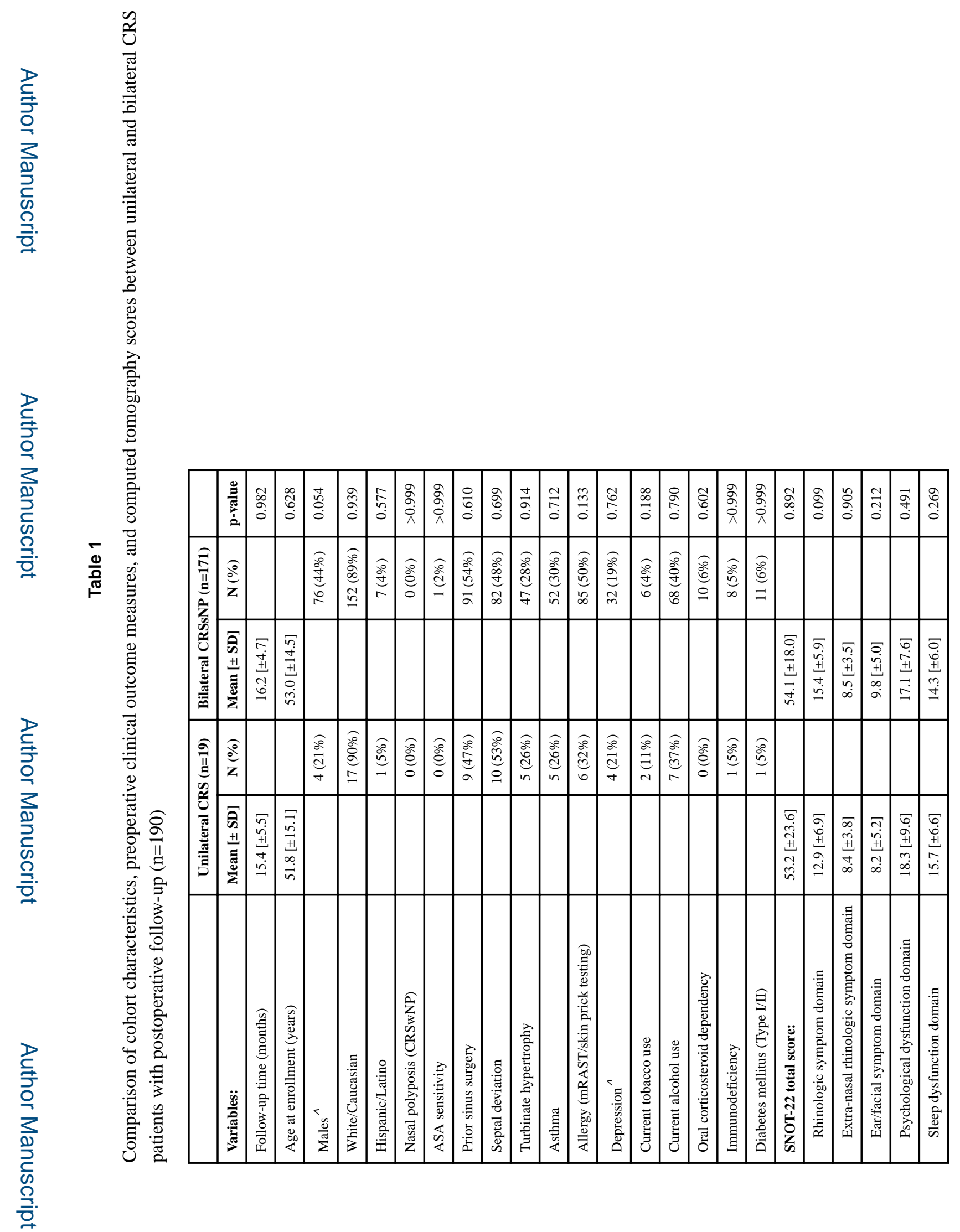

Int Forum Allergy Rhinol. Author manuscript; available in PMC 2018 December 01. 


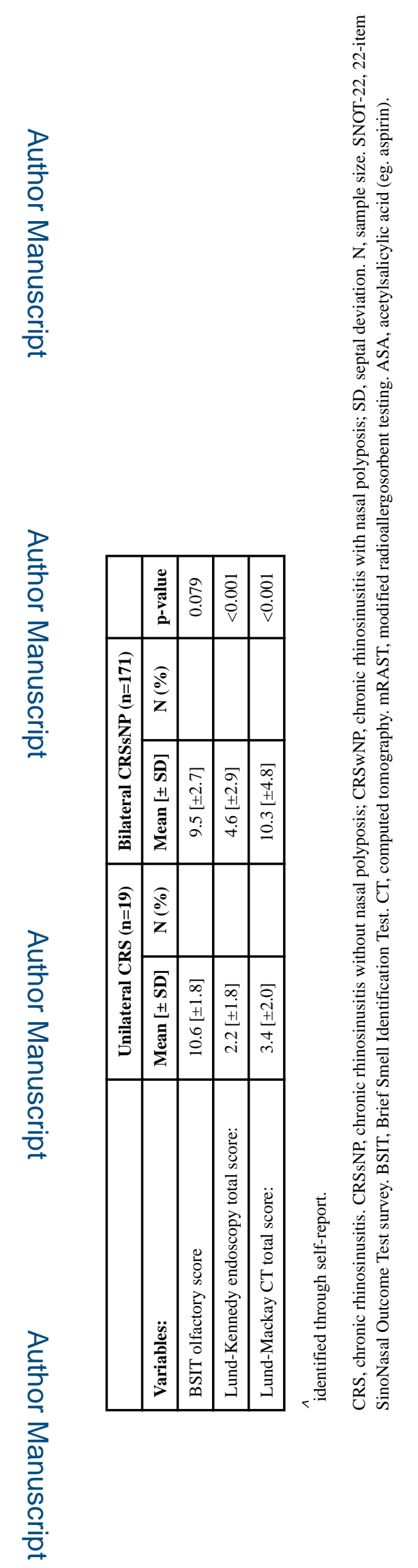

Int Forum Allergy Rhinol. Author manuscript; available in PMC 2018 December 01. 


\section{Table 2}

Surgical procedure prevalence between unilateral and bilateral CRS patients with postoperative follow-up $(\mathrm{n}=190)$

\begin{tabular}{|c|c|c|c|c|}
\hline \multirow{2}{*}{ Procedure type: } & \multicolumn{2}{|c|}{ Unilateral CRS $(n=19)$} & \multicolumn{2}{|c|}{ Bilateral CRSsNP $(n=171)$} \\
\hline & $\begin{array}{c}\text { Right side } \\
\mathbf{N}(\%)\end{array}$ & $\begin{array}{c}\text { Left side } \\
\text { N }(\%)\end{array}$ & $\begin{array}{c}\text { Right side } \\
\mathbf{N}(\%)\end{array}$ & $\begin{array}{c}\text { Left side } \\
\text { N }(\%)\end{array}$ \\
\hline Maxillary antrostomy & $11(58 \%)$ & $9(47 \%)$ & $158(92 \%)$ & $155(91 \%)$ \\
\hline Partial ethmoidectomy & $2(11 \%)$ & $7(37 \%)$ & $25(15 \%)$ & $25(15 \%)$ \\
\hline Total ethmoidectomy & $9(47 \%)$ & $4(21 \%)$ & $130(76 \%)$ & $127(74 \%)$ \\
\hline Sphenoidotomy & $9(47 \%)$ & $5(26 \%)$ & $107(63 \%)$ & $102(60 \%)$ \\
\hline Middle turbinate resection & $3(16 \%)$ & $1(5 \%)$ & $16(9 \%)$ & $15(9 \%)$ \\
\hline Inferior turbinate reduction & $7(37 \%)$ & $6(32 \%)$ & $44(26 \%)$ & $49(29 \%)$ \\
\hline Frontal sinustomy (Draf 1) & $0(0 \%)$ & $0(0 \%)$ & $18(11 \%)$ & $19(11 \%)$ \\
\hline Frontal sinusotomy (Draf 2a) & $1(5 \%)$ & $2(11 \%)$ & $74(43 \%)$ & $70(41 \%)$ \\
\hline Frontal sinusotomy (Draf 2b) & $2(11 \%)$ & $2(11 \%)$ & $8(5 \%)$ & $9(5 \%)$ \\
\hline Frontal sinusotomy (Draf 3) & \multicolumn{2}{|c|}{$0(0 \%)$} & \multicolumn{2}{|c|}{$0(0 \%)$} \\
\hline Septoplasty & \multicolumn{2}{|c|}{$9(47 \%)$} & \multicolumn{2}{|c|}{$82(48 \%)$} \\
\hline Image guidance & \multicolumn{2}{|c|}{$12(63 \%)$} & \multicolumn{2}{|c|}{$97(57 \%)$} \\
\hline
\end{tabular}

CRS, chronic rhinosinusitis; CRSsNP, chronic rhinosinusitis without nasal polyposis; N, sample size. 


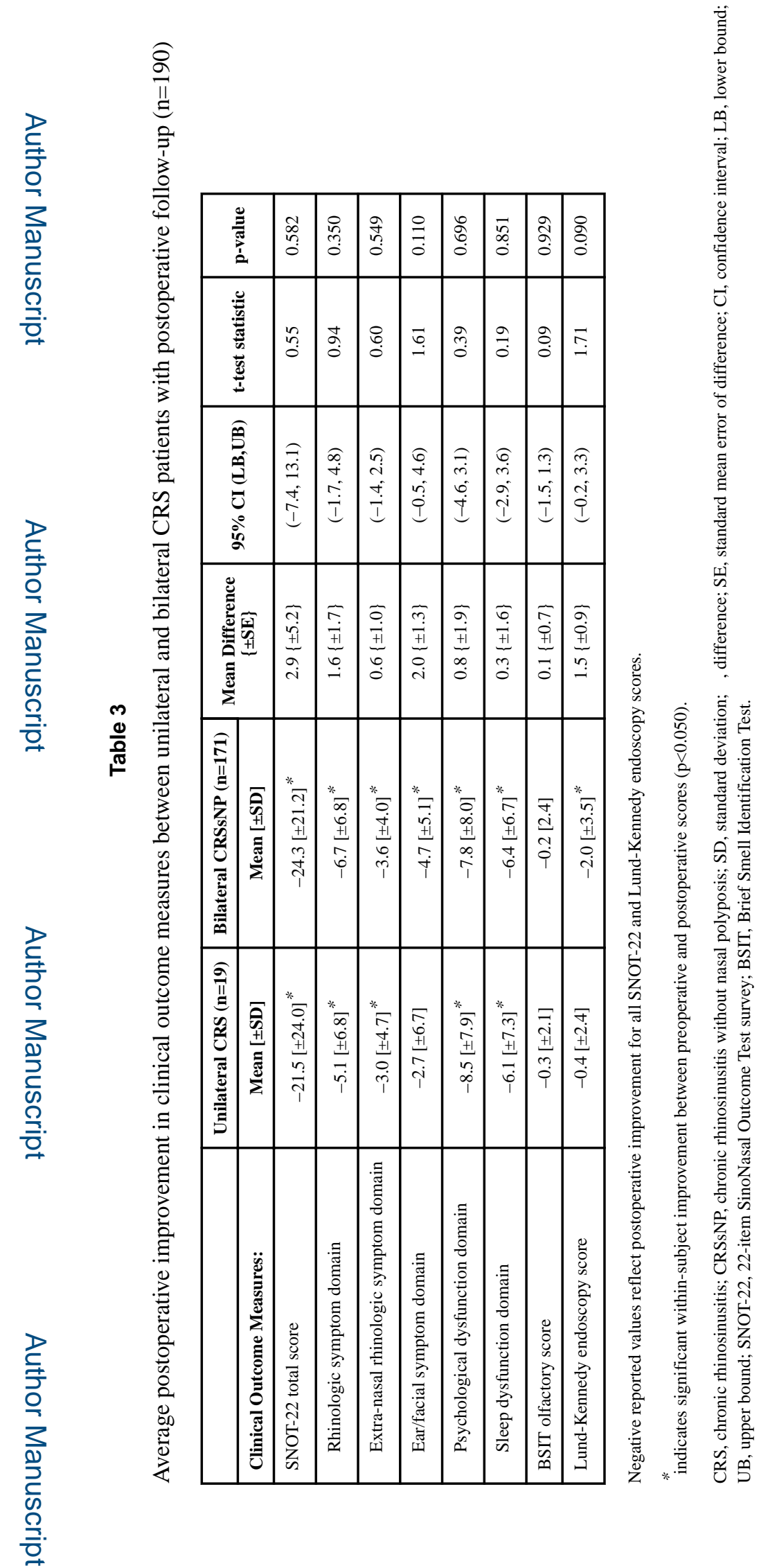

Int Forum Allergy Rhinol. Author manuscript; available in PMC 2018 December 01. 


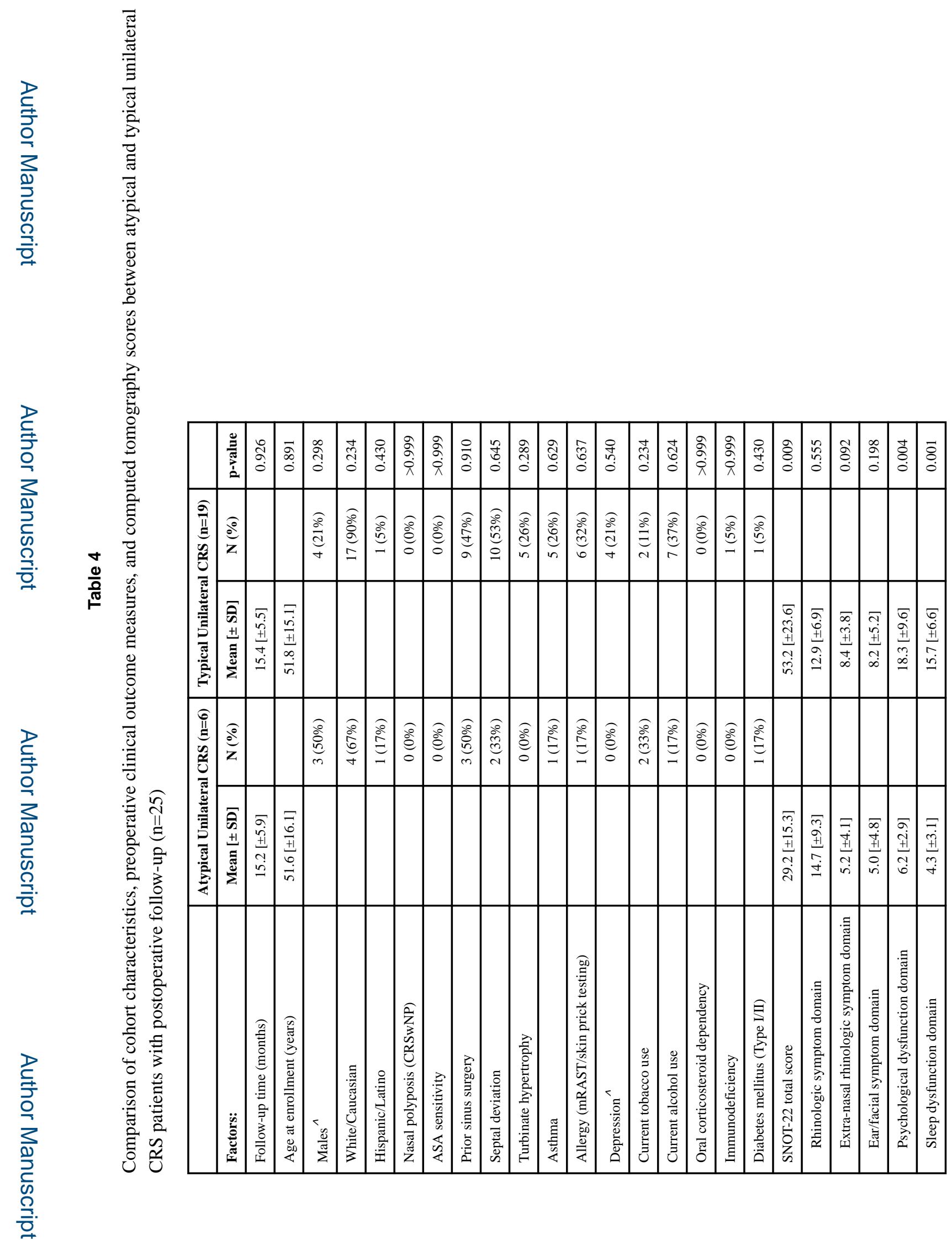

Int Forum Allergy Rhinol. Author manuscript; available in PMC 2018 December 01. 


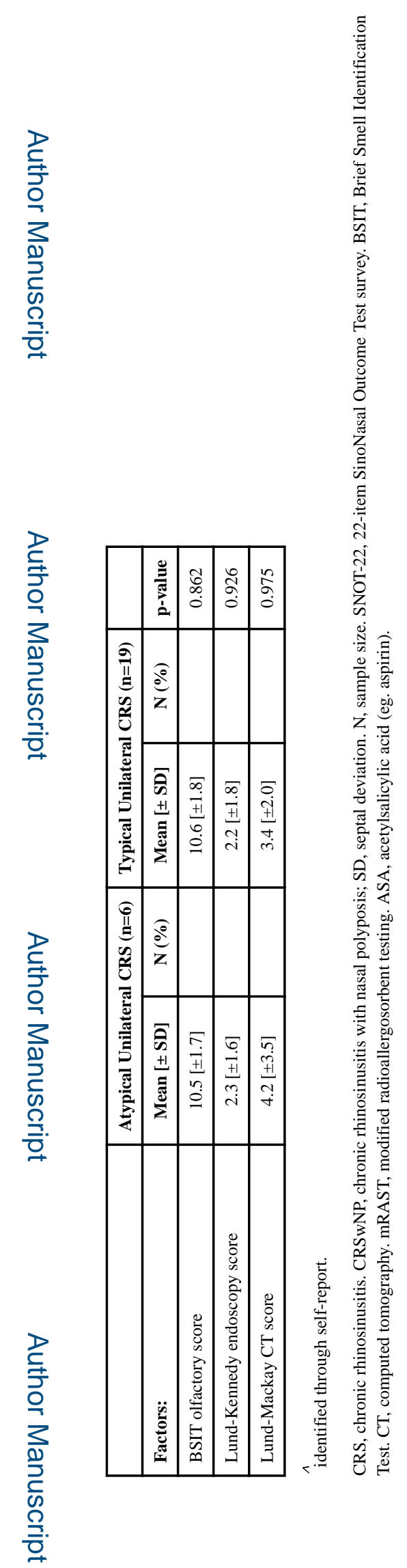

Int Forum Allergy Rhinol. Author manuscript; available in PMC 2018 December 01. 
Table 5

Surgical procedure prevalence between atypical and typical CRS patients with unilateral disease and postoperative follow-up $(n=25)$

\begin{tabular}{|l|c|c|c|c|}
\hline \multirow{2}{*}{ Procedure type: } & \multicolumn{2}{|c|}{ Atypical Unilateral CRS (n=6) } & \multicolumn{2}{c|}{ Typical Unilateral CRS (n=19) } \\
\cline { 2 - 5 } & $\begin{array}{c}\text { Right side } \\
\text { N (\%) }\end{array}$ & $\begin{array}{c}\text { Left side } \\
\text { N (\%) }\end{array}$ & $\begin{array}{c}\text { Right side } \\
\text { N (\%) }\end{array}$ & $\begin{array}{c}\text { Left side } \\
\text { N (\%) }\end{array}$ \\
\hline Maxillary antrostomy & $1(17 \%)$ & $6(100 \%)$ & $11(58 \%)$ & $9(47 \%)$ \\
\hline Partial ethmoidectomy & $0(0 \%)$ & $1(17 \%)$ & $2(11 \%)$ & $7(37 \%)$ \\
\hline Total ethmoidectomy & $1(17 \%)$ & $3(50 \%)$ & $9(47 \%)$ & $4(21 \%)$ \\
\hline Sphenoidotomy & $0(0 \%)$ & $0(0 \%)$ & $9(47 \%)$ & $5(26 \%)$ \\
\hline Middle turbinate resection & $0(0 \%)$ & $1(17 \%)$ & $3(16 \%)$ & $1(5 \%)$ \\
\hline Inferior turbinate reduction & $2(33 \%)$ & $2(33 \%)$ & $7(37 \%)$ & $6(32 \%)$ \\
\hline Frontal sinustomy (Draf I) & $0(0 \%)$ & $0(0 \%)$ & $0(0 \%)$ & $0(0 \%)$ \\
\hline Frontal sinusotomy (Draf IIa) & $0(0 \%)$ & $0(0 \%)$ & $1(5 \%)$ & $2(11 \%)$ \\
\hline Frontal sinusotomy (Draf IIb) & $0(0 \%)$ & $1(17 \%)$ & $2(11 \%)$ & $2(11 \%)$ \\
\hline Frontal sinusotomy (Draf III) & \multicolumn{3}{|c|}{$0(0 \%)$} & \multicolumn{2}{|c|}{$0(0 \%)$} \\
\hline Septoplasty & \multicolumn{3}{|c|}{$2(33 \%)$} & $(47 \%)$ \\
\hline Image guidance & \multicolumn{2}{|c|}{$12(63 \%)$} \\
\hline
\end{tabular}

CRS, chronic rhinosinusitis. N, sample size. 


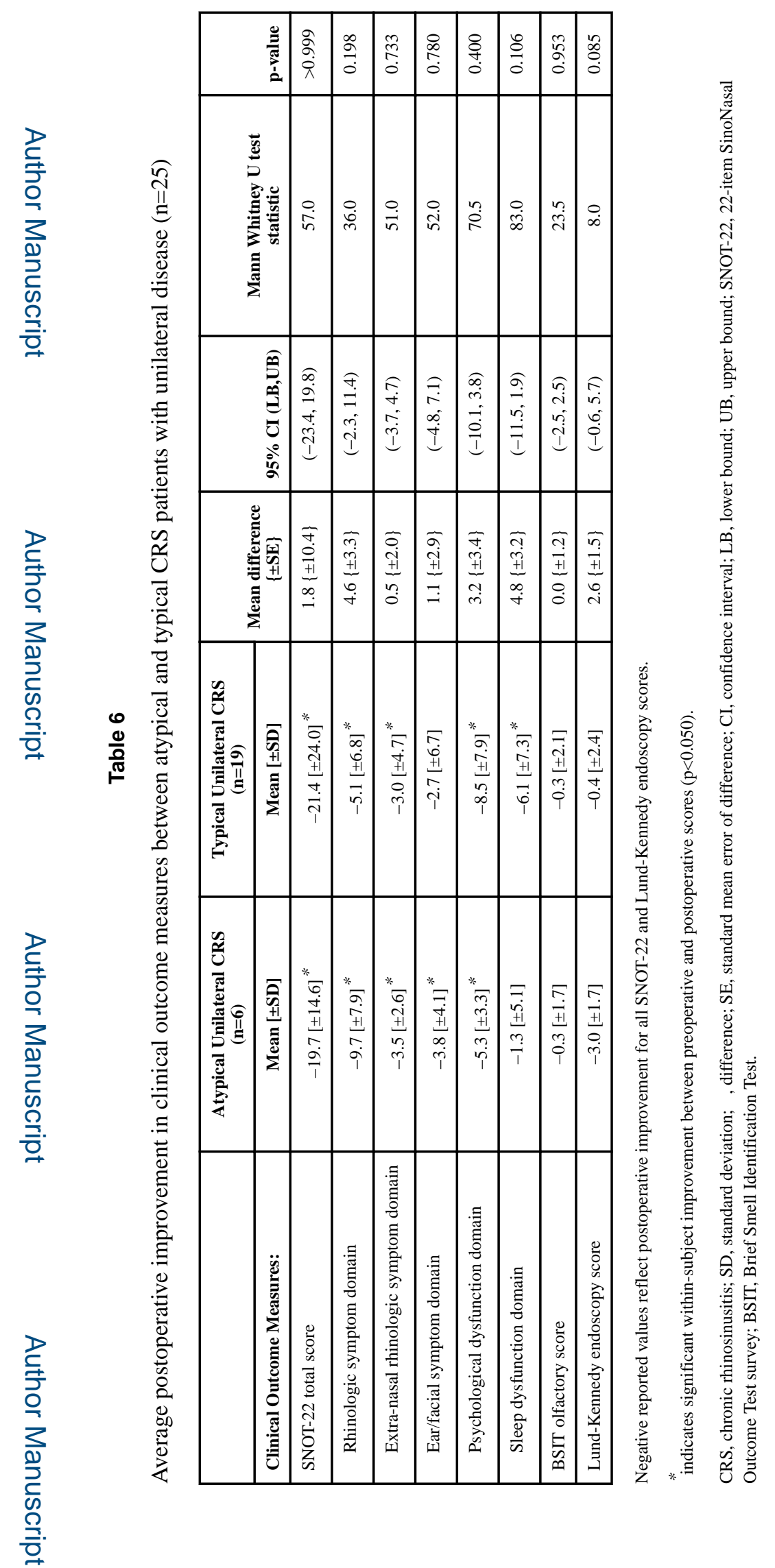

Int Forum Allergy Rhinol. Author manuscript; available in PMC 2018 December 01. 